The Brock Review Volume 10, Number 2 (2009)

(C) Brock University

\title{
A Schizophrenia
}

\author{
Richard Boulet \\ University of Alberta
}

Artist Statement: Holding the threaded needle in my hand, I start at the back of the cloth; through, across, down, up, across, down again. I have completed one square of a cross-stitch. I will eventually complete my cross-stitch if I repeat this action many times over. I will then start another. There is an automatic physical precision to this activity. Success is guaranteed with a few carefully calculated design decisions. A mental framework can take form from such a rigid situation. My involvement with the cross-stitch gives me a tangible feeling of being in the moment plus my thoughts are able to delve into the past, my previous psychotic life before being diagnosed with schizophrenia and my mental health recovery. I allow for such rumination as, quite frankly, I need to make sense of this schizophrenia situation and give it peace.

The only other times my art practice had such a precise calculated effort was when I was psychotic. I made a mobile in Winnipeg that I thought connected all human knowledge, many small folded pieces of paper with coded symbols in Vancouver and an Ex Voto in Calgary for mental suffering. This was made from a magazine. None of this work survives. The lesson I take from the memory of these psychotic art works is that even in such a precarious state as psychosis, it is possible to focus sharply and survive. I can cross-stitch, think these thoughts and also stay in the present, my healthy present, feel proud I have made it this far in recovery and keep working.

The machine sewing techniques for the fibre pieces are quilt based. I took a few courses in quilting. Then I made a quilt for my bed. This quilt made me feel I could truly care for my self. I could create my own nurtured, feminine gestures for my home. A quilt for the couch and the easy chair soon followed. When my MFA is over I'm going to make a new quilt for my bed, an elaborate appliqué of whimsical birds in a quirky landscape. A new lease on life requires a new quilt, fitting to the potential of the future.

When I use quilting techniques in my work for my Masters, these feelings of carefully tended home follow me to the studio. The fibre pieces use large text to assertively proclaim: "This is schizophrenia. This is also sewing. Mix the two and hope through careful nurturing is possible." The cross-stitch text and images say: "Take it easy, one small step at a time. With patience and diligence a delicate, precious completion is possible." With cross-stitch and quilting I feel I am understanding that work learned in a safe home can follow me into the world and add strength to my character to do more than just survive. I can flourish. Is this the traditional quiet message behind all the sewing and stitching created by countless mothers for their families?

My drawing for my MFA has a much different job to accomplish. This is when I mentally let loose. I let my mind slide into the energy of the atavistic schizophrenic experience. I jump into the psychotic with abandon and see what I can pull out by the seat of my pants. The drawing is testing ground to see if I have finally managed to recover to the point that there is no danger lurking in my mind. What I feel protects me from such a swim is all I have been taught about drawing during my BFA and my MFA and the practicing that occurred in the years between these two degrees. Yes, delving into the psychotic could seem to be a dangerous move but rules do exist, drawing rules that were learnt in university and on my own. Does this drawing of a particular schizophrenic experience 
need a little more dark yellow here, or a fine line there? It is the sublime training of experience applied to the task at hand that allows the psychosis of the past to be investigated and given light without fear of mental instability.

There is cross-stitch and quilt sewing for creating a home for myself no matter where I wander and drawing for testing my sanity.

\section{Notes On Specific Works}

Neologism (p. 63, detail p. 64): Quite often people in the midst of psychotic thinking speak in altered speech patterns. It can be quite difficult to convince a person who is in psychosis to accept treatment.

Step $1 A A A A$ (p.65): One of the strategies for mental health recover I was exposed to early on was goal planning.

No Longer Homeless (p.66, detail p.67): I was living marginally in various Canadian cities for about two years before my diagnosis. I did live briefly in homeless shelters in Vancouver and Calgary. The majority of the time was spent living in rooming houses with welfare funding and occasional short term employment.

The drawings (p. 68, 69 \& 70) are, quite simply, an expression of a more immediate, visceral, less planned and instinctual interpretation of the banner topics.

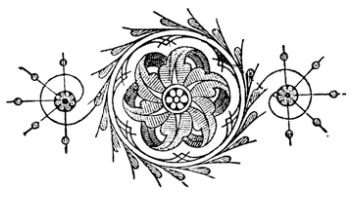




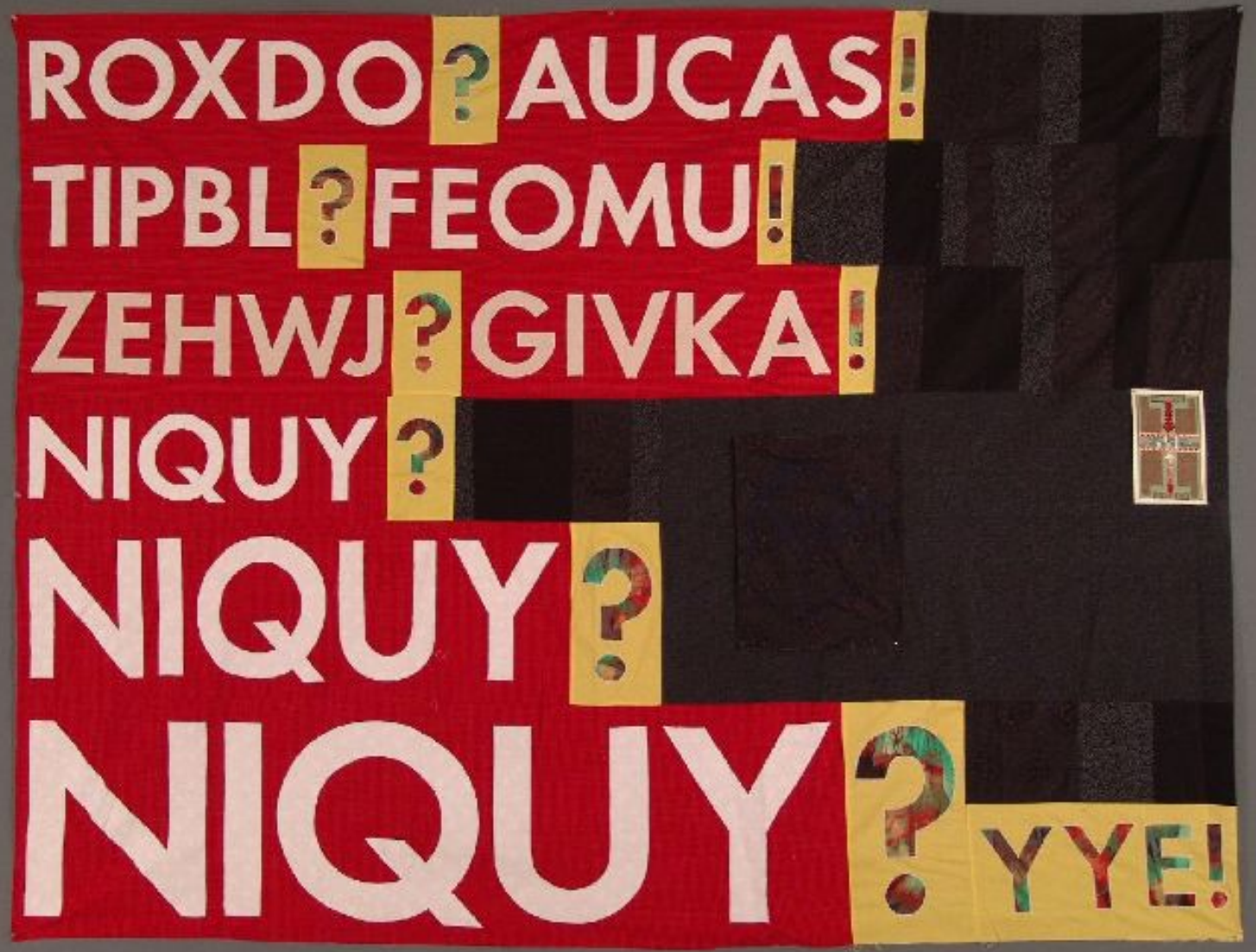

Richard Boulet, Neologism (fabric appliqué and cross-stitch, 68” x 91”), 2004 (see detail on the following page) 


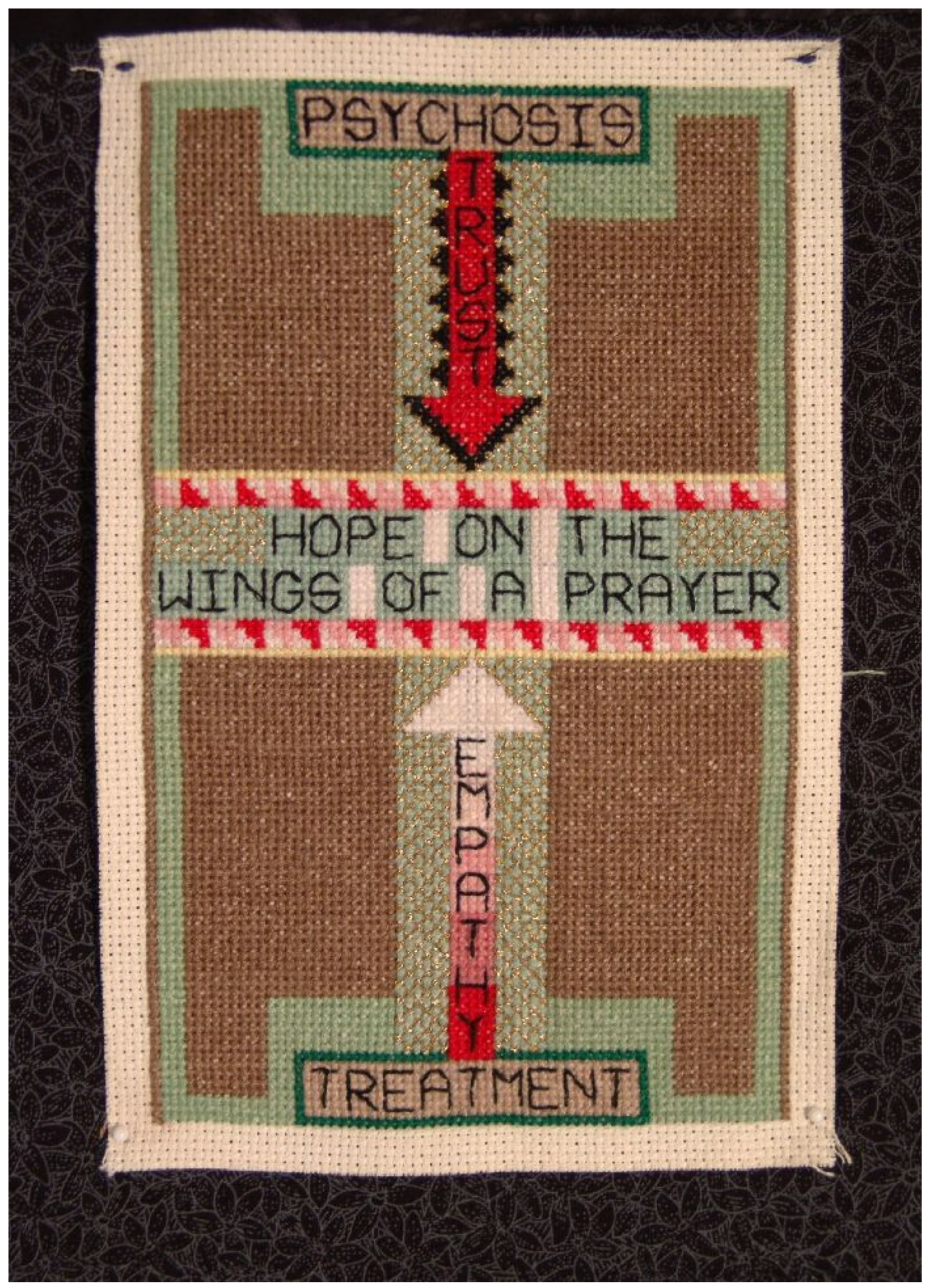




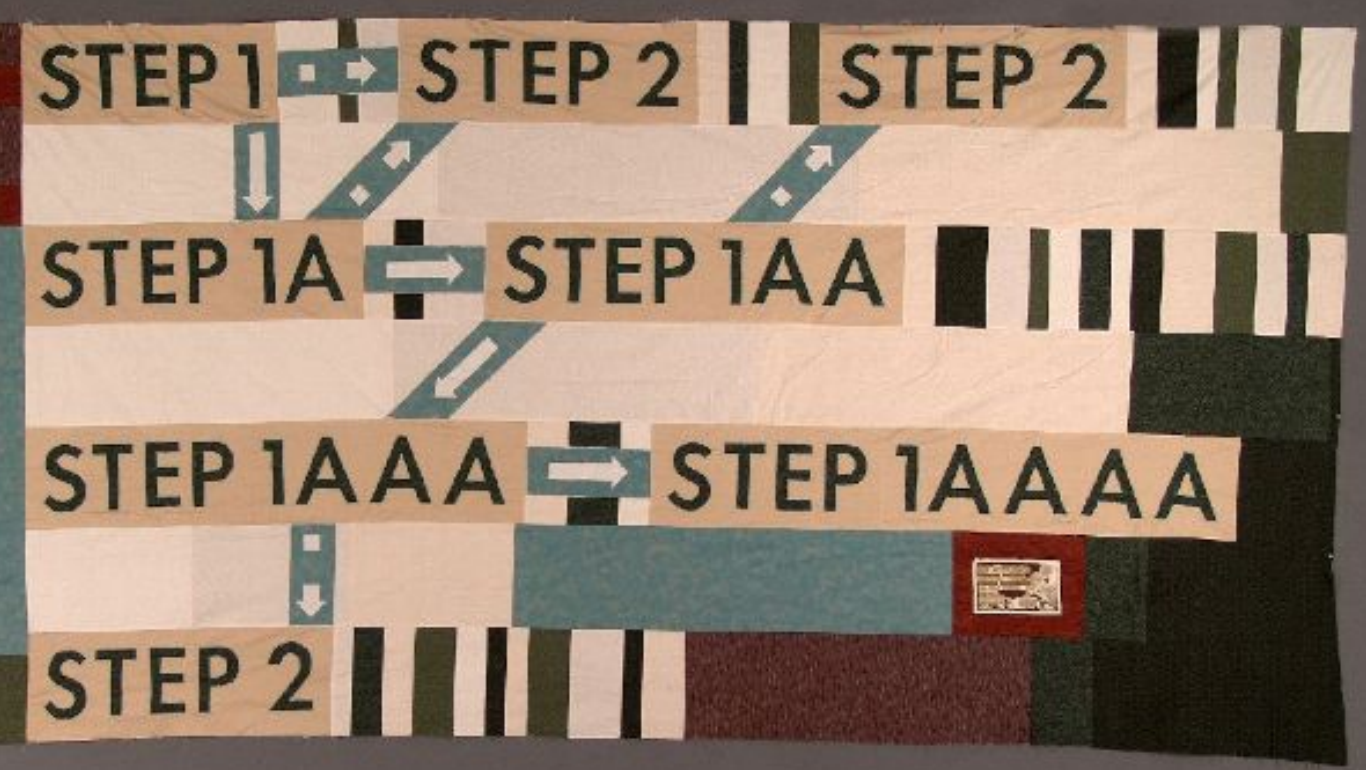

Richard Boulet, Step 1AAAA (fabric appliqué and cross-stitch, 66” x 144”), 2004 (see detail below)

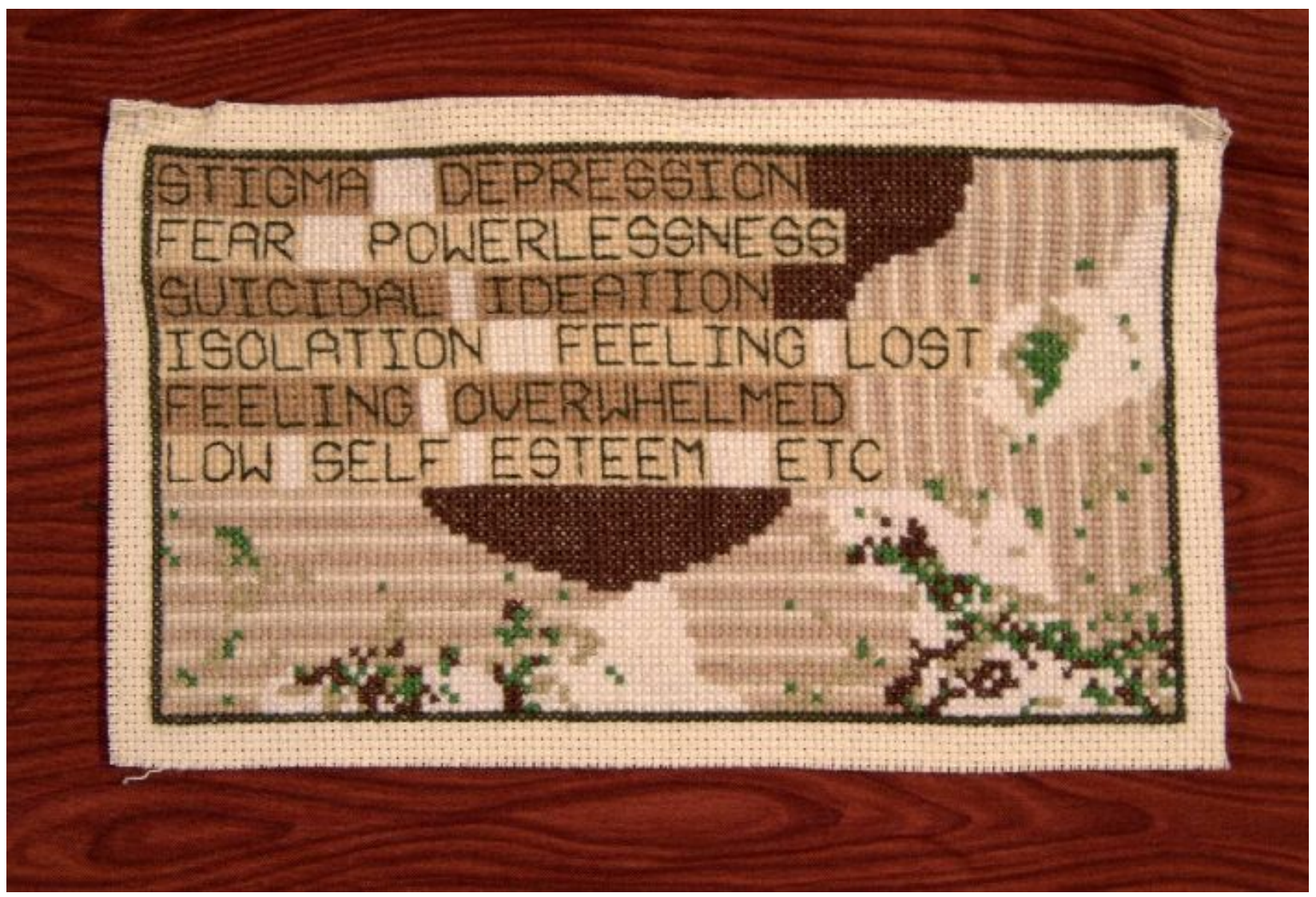




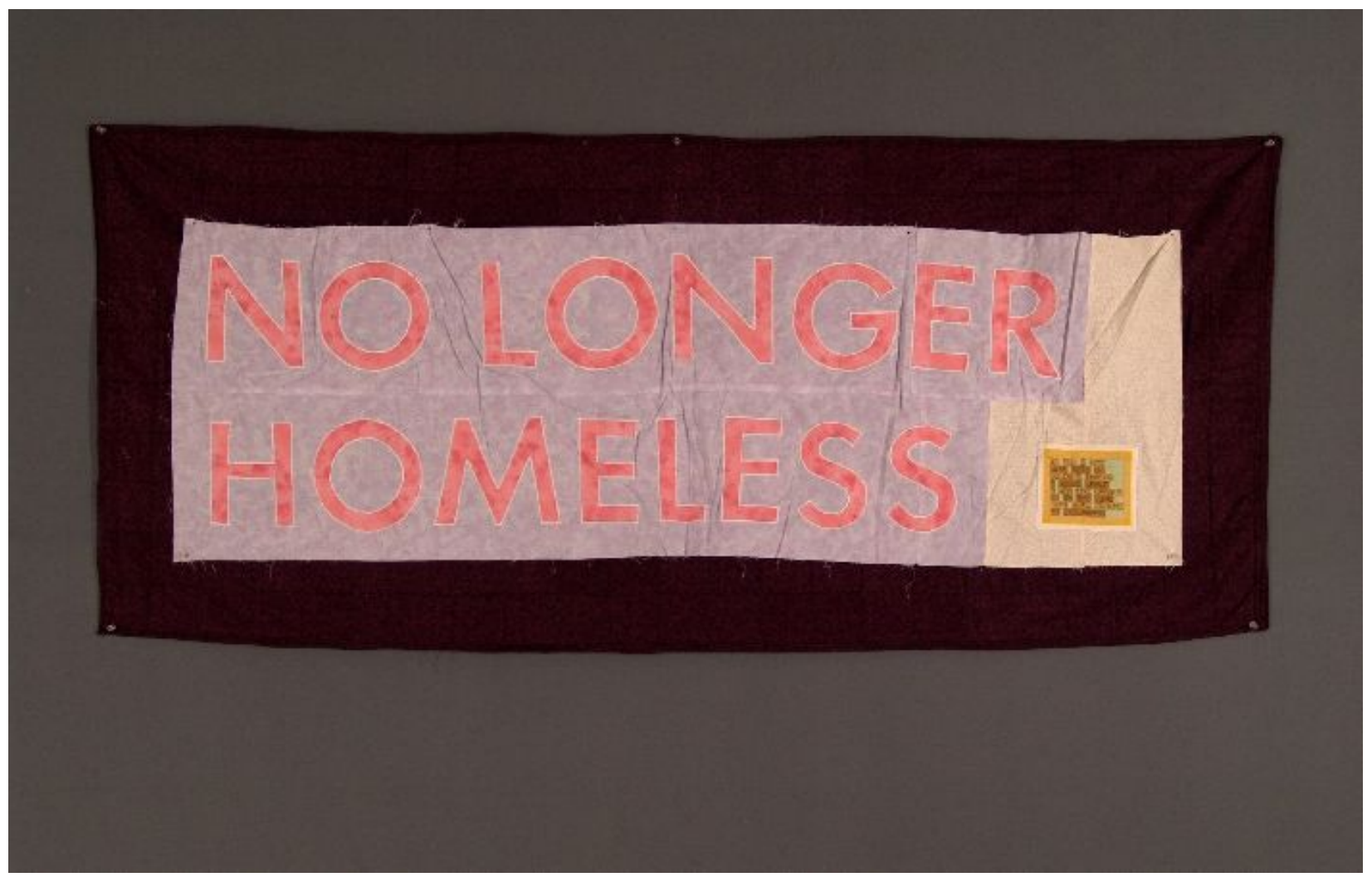

Richard Boulet, No Longer Homeless (fabric appliqué and cross-stitch, 29” x 66”), 2004 (see detail on following page) 


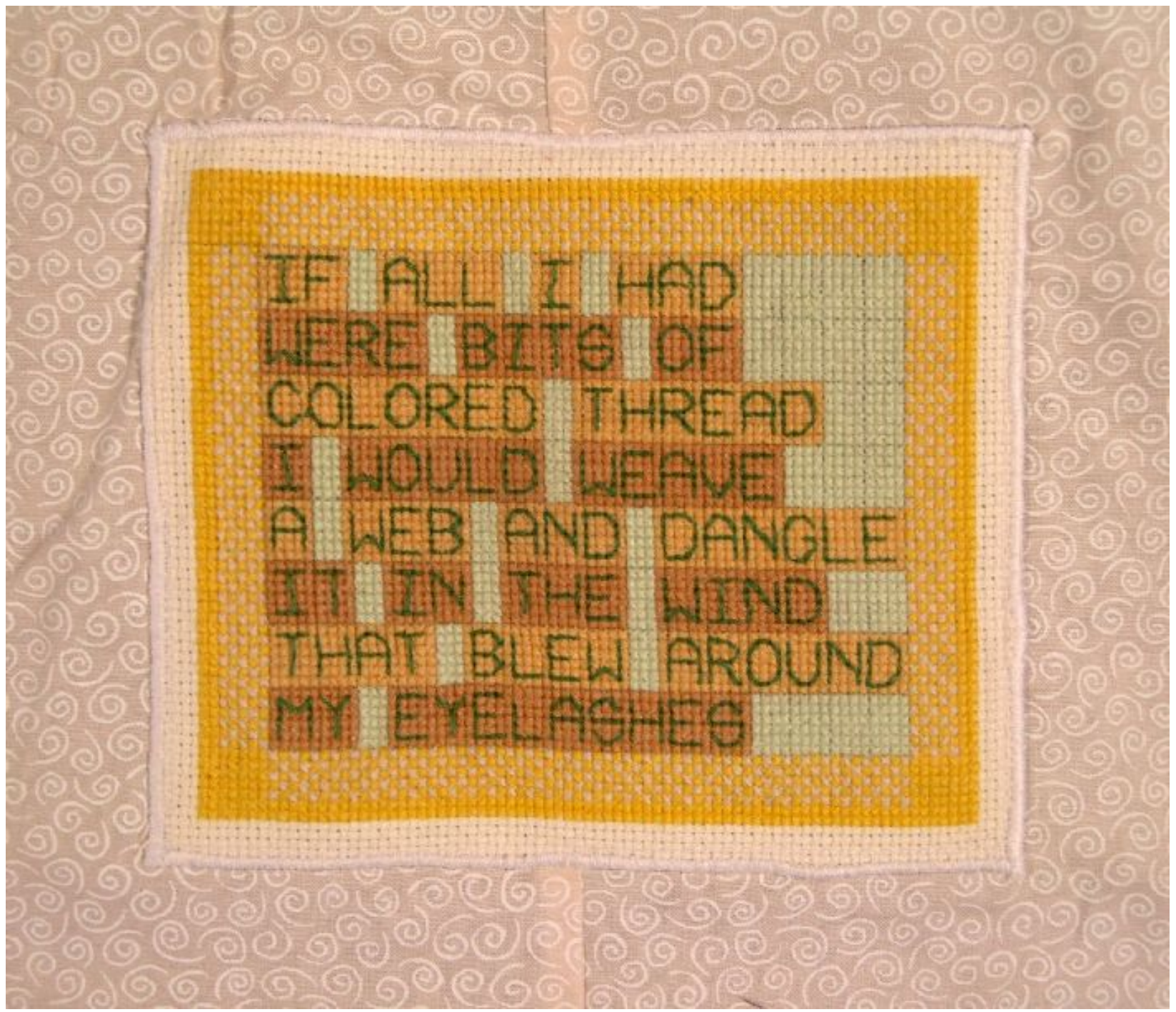




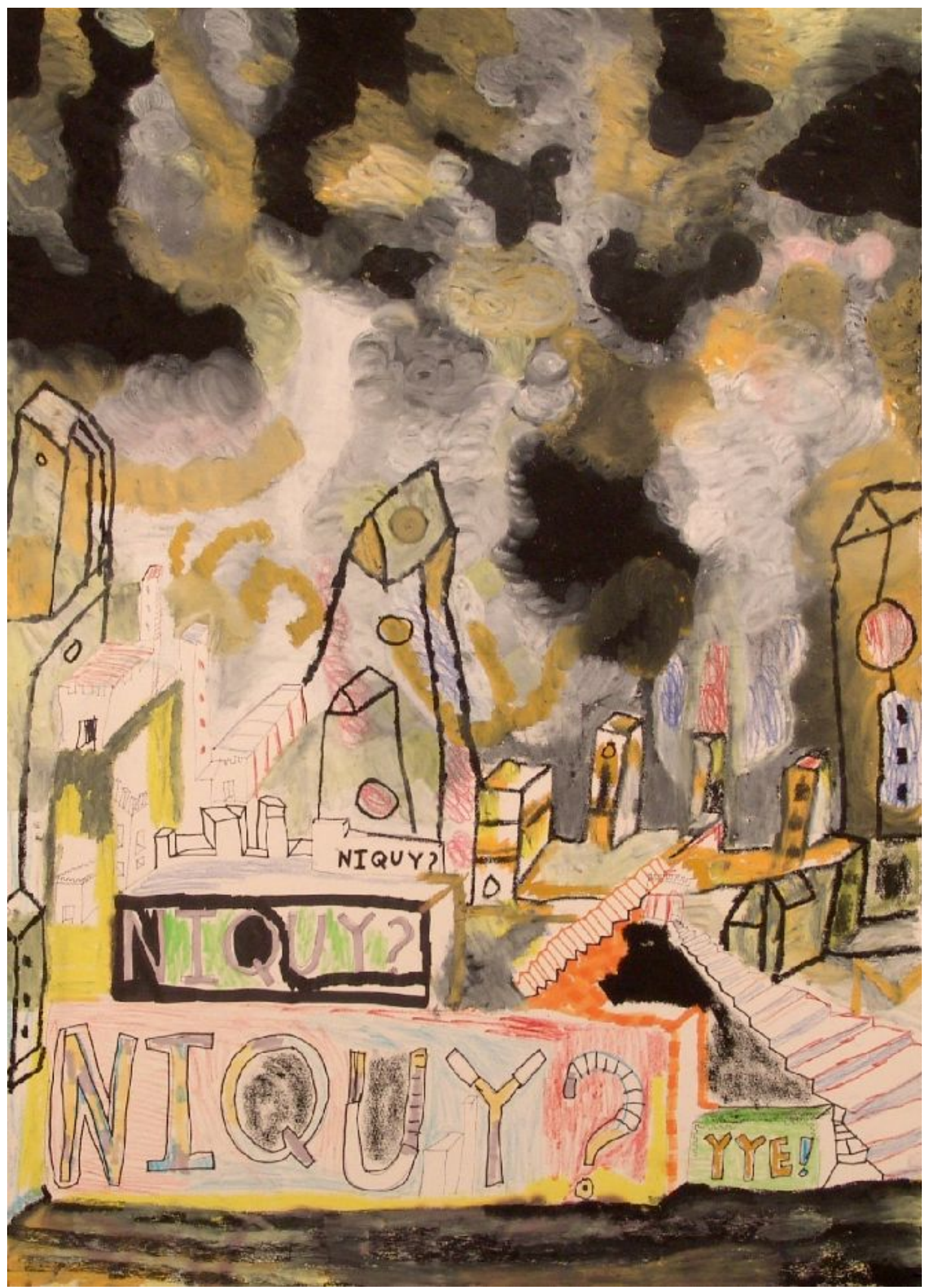

Richard Boulet, Neologism Drawing (mixed media, 41 1/4” x 29 1/2”), 2005 


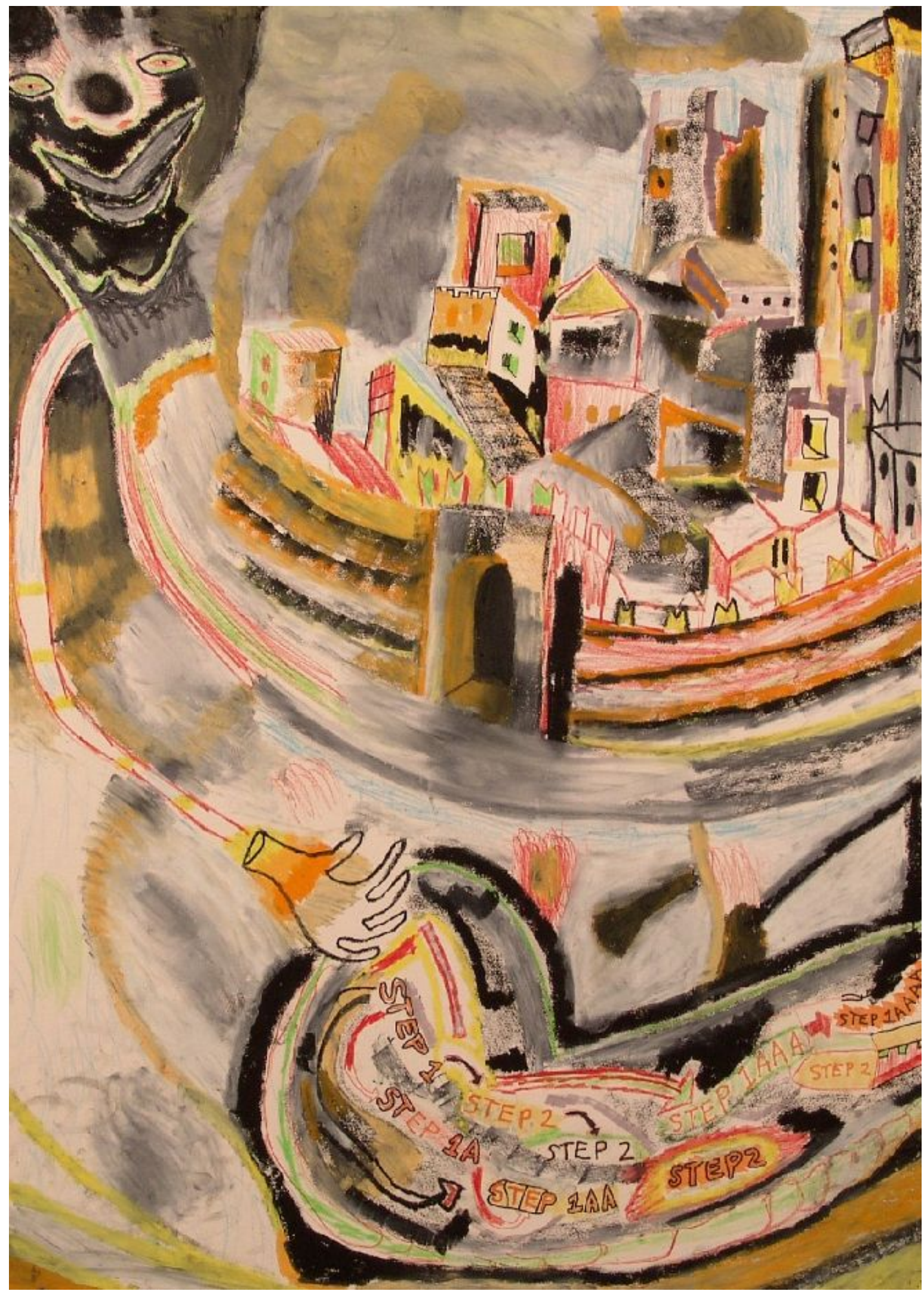

Richard Boulet, Step 1 AAAA Drawing (mixed media, 41 1/4” x 29 1/2”), 2005 


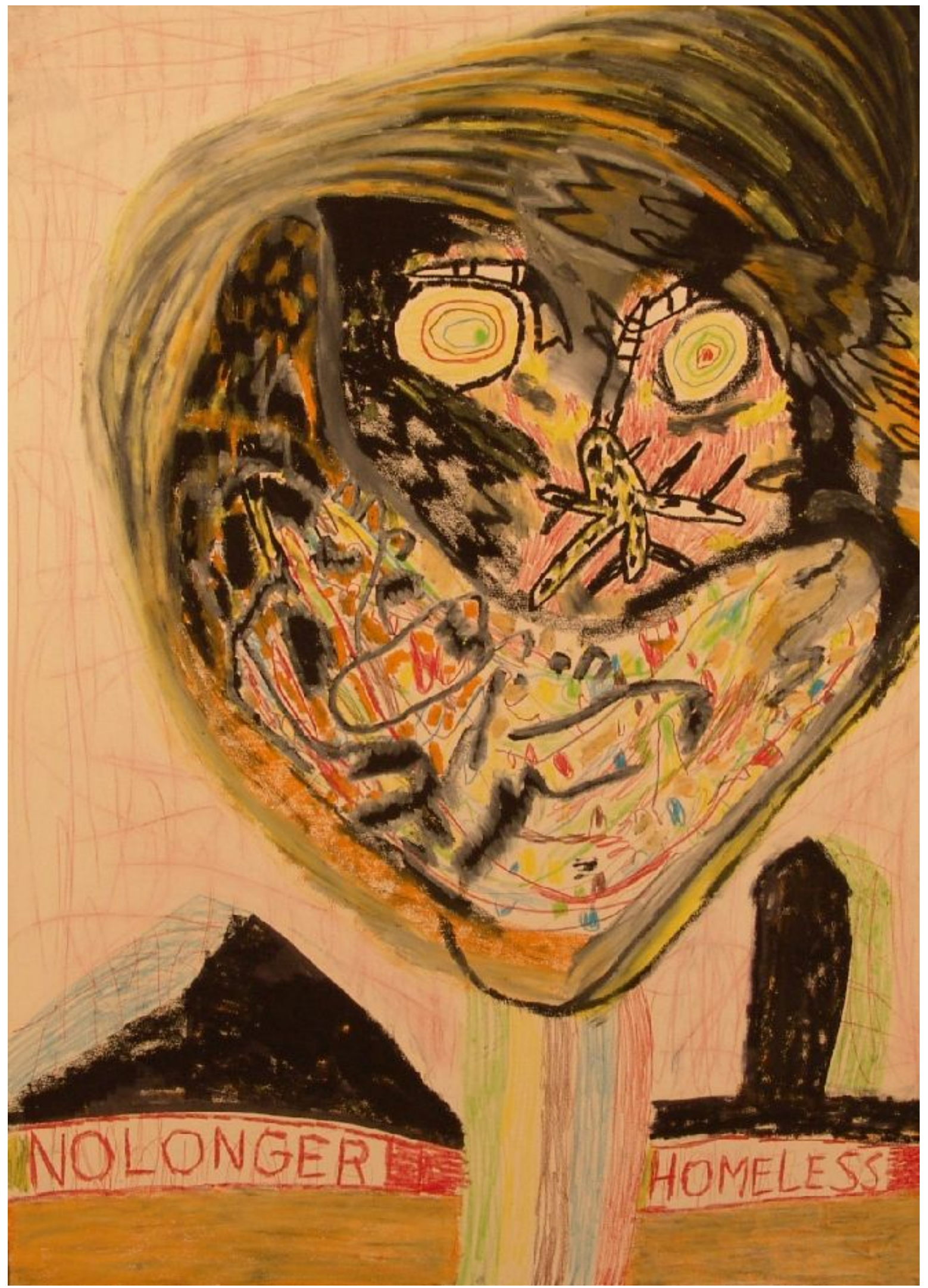

Richard Boulet, No Longer Homeless Drawing (mixed media, 41 1/4” x 29 1/2”), 2005 